\title{
The impacts of La Niña-induced drought on Indian Vulture Gyps indicus populations in Western Rajasthan
}

\author{
JONATHAN C. HALL, ANIL K. CHHANGANI, TOM A. WAITE and \\ IAN M. HAMILTON
}

\begin{abstract}
Summary
Previous research on the catastrophic decline of the Gyps species complex has identified diclofenac, a non-steroidal anti-inflammatory drug administered to livestock, as the primary cause. Largescale climatic phenomena, such as ENSO-induced drought, however have not been examined. Based on time series analysis of annual count data, 1996-2005, we provide evidence that ENSO synchronised population dynamics throughout western Rajasthan. Here, we ask whether El Niño Southern Oscillation (ENSO) can also explain the population dynamics of the Critically Endangered Indian Vulture Gyps indicus. We attribute this impact largely to two La Niña events, including the major event spanning 1999. We also examine between-village variation in resident vulture populations. Our results suggest that in several villages, Indian Vulture populations may have been partially buffered from the negative effects of drought when compared to other villages in the study. Finally, we discuss potential causes of buffering in these villages.
\end{abstract}

\section{Introduction}

Vulture species across the globe face numerous threats to their survival. Many of these challenges are the result of human persecution, development, and unintentional poisoning (Green et al. 2004, Oaks et al. 2004, Hernández 2008, Margalida 2008, Hernández and Margalida 2009). Catastrophic declines of vultures belonging to the genus Gyps have been documented throughout India and Pakistan, as well as more widely across the Indian sub-continent, in recent years (Prakash 1999, Prakash et al. 2003, Gilbert et al. 2002, Oaks et al. 2004, Hla et al. in press, Chaudhary et al. in press). The first early warning sign was detected in India's Keoladeo National Park in the 1990s, when White-backed Vultures Gyps bengalensis, then one of the most common raptors on the Indian subcontinent, began a massive decline (Prakash 1999). Since then, catastrophic declines, also involving the Indian Gyps indicus, formerly G. indicus indicus and Slender-billed Vulture Gyps tenuirostris, formerly G. indicus tenuirostris, have been reported across the subcontinent (Prakash et al. 2003). Not surprisingly, these species are now listed as 'Critically Endangered' (BirdLife International 2009) and a flurry of research activity has attempted to identify the underlying cause of these population crashes.

These crashes have been largely attributed to poisoning by diclofenac, a non-steroidal antiinflammatory drug used widely to treat sick and arthritic livestock (Green et al. 2004, 2006, Oaks et al. 2004, Shultz et al. 2004, Taggart et al. 2006, Taggart et al. 2007, Das et al. 2011). Vultures that feed on diclofenac-laced carcasses can suffer renal failure and visceral gout (Oaks et al., 2004, Shultz et al. 2004, Swan et al. 2006), which caused high mortality and led to dramatic population declines (34-95\%) of White-backed Vultures in Pakistan between 2000 and 2003 (Oaks et al. 2004). A follow-up study purported to show that diclofenac concentrations in livestock carcasses 
were sufficient to explain documented declines of all three above mentioned Gyps species across the Indian subcontinent (Green et al. 2006). The evidence that diclofenac played a key causal role in the vulture die-off is compelling.

However, the potential role of climate in connection with vulture declines has not been thoroughly explored thus far. There is a growing body of evidence that climatic factors including El Niño Southern Oscillation (ENSO) events can have dramatic negative effects on populations (Chhangani 2004, 2005, Chhangani and Mohnot 2004, Waite 2007a,b, Chhangani and Sivaperuman 2009). In arid regions, ENSO alternates between El Niño events leading to rainfall and La Niña events leading to drought. By suppressing plant growth and recruitment, drought can have bottomup trophic effects (Holmgren and Scheffer 2001), leading to vertebrate population crashes (Harrison 2000, Cleary et al. 2006). In the case of the recent crash of Gyps spp., the role of climate seems worth considering because the crash coincided with the major ENSO-induced drought of 2000, which apparently caused a simultaneous decline of the mammal community in a nearby wildlife sanctuary in the Aravalli Hills (Waite et al. 2007a). Given the widespread use of diclofenac among livestock (Green et al. 2004) it seems plausible that the coincidental crash of vultures could have been exacerbated by the same ENSO-induced drought.

Here, we examine the impact of ENSO on population dynamics of the Indian Vulture at II village sites scattered throughout western Rajasthan, India. We ask whether ENSO-induced drought synchronised population dynamics across the region. We also model village-specific vulture population growth rates in order to discover which variables contributed to respective trends in vulture populations over time.

\section{Methods}

\section{Study area}

The study area was situated within $175 \mathrm{~km}$ of Jodhpur $\left(26^{\circ} 18^{\prime} \mathrm{N}, 73^{\circ} \mathrm{O} 8^{\prime} \mathrm{E}\right)$, a major city (population $\sim 1.5$ million) in western Rajasthan (Figure 1 ), at the eastern edge of the Great Indian (Thar) Desert. The region is covered with open scrub forest. Dominant tree and shrub species include: Acacia senegal, A. nilotica, Euphorbia caducifolia, Anogeissus pendula, Mytenus emarginata, Grewia tenax, Ziziphus nummularia, Prosopis cineraria, Capparis decidua, Tecomella undulata and the exotic invasive Prosopis juliflora. Temperatures can reach highs of $\sim 48^{\circ} \mathrm{C}$ in May and June, and lows of $\sim 1^{\circ} \mathrm{C}$ during winter. Annual rainfall averages $360 \mathrm{~mm}$, with $90 \%$ occurring during the monsoon season (July-September). Monsoon failure can lead to hydrological and vegetative drought.

Villages are composed of a central housing complex (multiple homes all within $1 \mathrm{~km}$ of each other) and surrounding agricultural and community lands. Boundaries between villages are established via landmarks on individual or village lands.

\section{Study species}

The Indian Vulture is a large $(5.5-6.3 \mathrm{~kg})$ scavenging raptor found almost throughout the Indian subcontinent (for a detailed description see Ferguson-Lees et al. 2001, BirdLife International 2009). The Indian Vulture feeds almost exclusively on carrion, mostly livestock carcasses. It typically nests in colonies on cliffs or crags, but also nests in trees where rocky habitat is unavailable (Chhangani and Monot 2004, Chhangani 2005, Chhangani and Sivaperuman 2009). Nesting begins in November and lasts until May, with successful pairs raising one offspring per breeding season.

The Indian Vulture was recently granted species status, when two subspecies of the Long-billed Vulture were split into Indian and Slender-billed Vultures (Rasmussen and Parry 2001). Despite morphological similarities, and some overlap in geographic range between these species, we can state confidently that we collected data on Indian Vultures only. None of our vultures showed the 

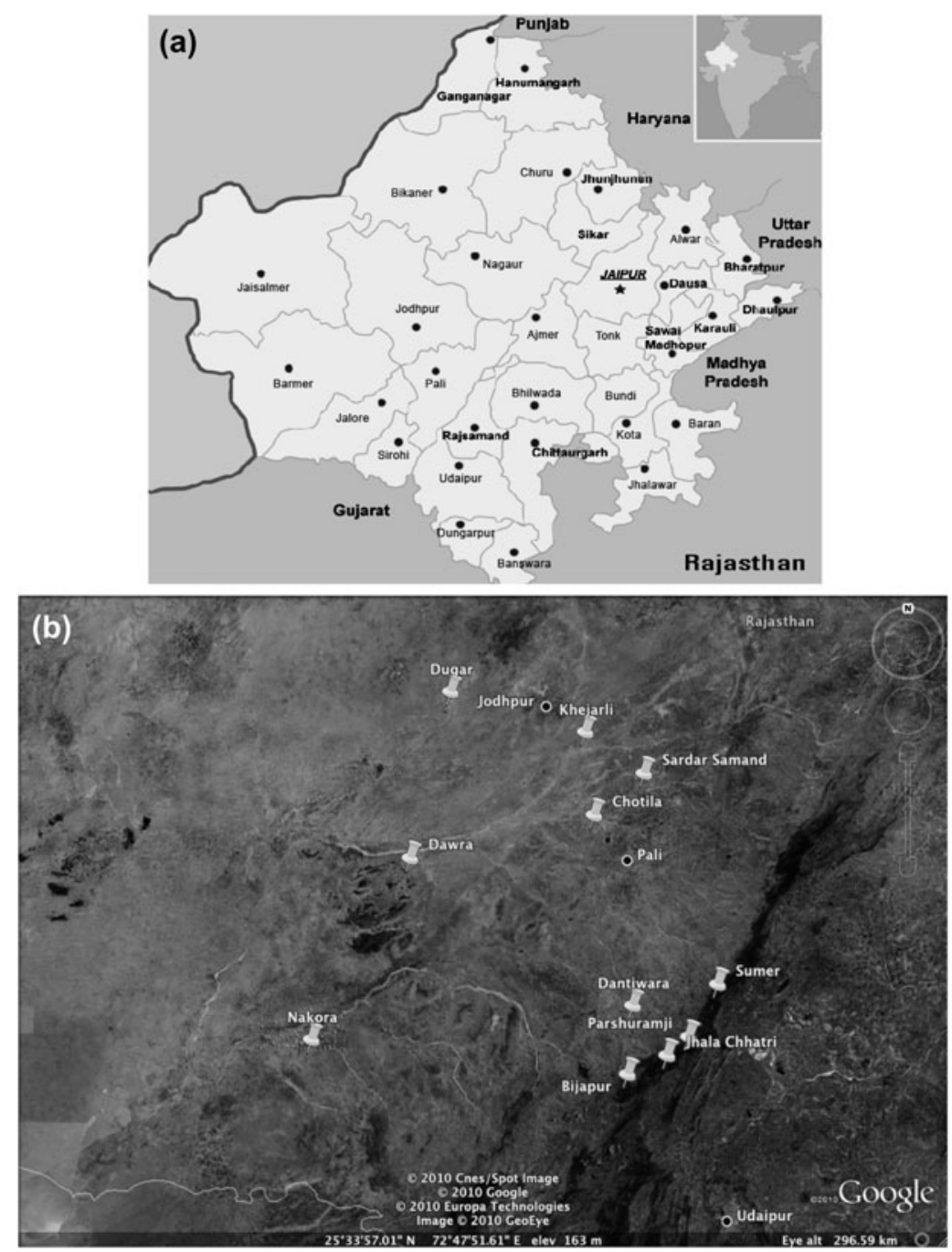

Figure 1. a) Map of Rajasthan. b) Map of village locations in relation to the major cities Jodhpur and Pali. Push pin icons mark village sites.

diagnostic field marks of Slender-billed Vulture (slender bill and dark brown plumage on body and head; Ferguson-Lees et al. 2001) and none of the local populations we monitored occurred in the area of known overlap in geographic ranges (IUCN 2007).

\section{Field methods}

Monitoring of vultures in and around 11 villages within $175 \mathrm{~km}$ of the city of Jodhpur (Figure 1 ) began in winter 1996/1997. Annual counts were conducted until 2004/2005. Vultures were counted at known nesting sites within each village in trees and rock formations. Local villagers were often consulted as to where they had observed vulture nesting sites. Observations were also made from vehicles during road transects and opportunistically during periodic visits to villages in the region. Adult breeding pairs were counted and recorded as two individuals along with 
offspring in each respective nest. The known local breeding populations included in our analysis were surveyed extensively during each nesting season.

These data provide an index of local abundance of Indian Vultures during the nesting season. Because vultures were not individually identifiable, and because our monitoring efforts were periodic rather than continuous, we do not know the precise relationship between observed and actual abundance. Therefore, our analysis is based on the assumption that the index of abundance is proportional to actual abundance and that this proportionality holds steady across years and locations.

\section{Climate data}

We used an El Niño Southern Oscillation (ENSO) index as a predictor of Indian Vulture population dynamics. ENSO is the most important oceanic-atmospheric driver of year-to-year variability in global climate. We used the Multivariate ENSO Index (MEI) (http://www.cdc.noaa. gov/people/klaus.wolter/MEI/mei.html\#ref_wt1), which is based on six variables observed over the tropical Pacific Ocean: sea-level pressure, zonal and meridional components of surface wind, sea surface temperature, surface air temperature, and total fractional cloudiness. MEI is computed for sliding bimonthly periods, and standardised with respect to season and the reference interval 1950-1993. We used mean MEI values during winter, December-February. Negative values represent the cold ENSO phase (La Niña), while positive values represent the warm ENSO phase (El Niño).

\section{Data analysis}

All the time-series described below were analysed using SPSS (2007). All statistical tests were two-tailed.

\section{Cross-correlation, 'Leave-one-out' analysis of synchrony}

To evaluate whether ENSO might have synchronised Indian Vulture population dynamics across the region, we began by cross-correlating (lag $=0$ ) the time series of the local populations. We did so after first transforming (natural logarithm) and differing ( $\mathrm{I}$ year) the data, thereby converting the time series of raw count data into time series of annual population growth rates (i.e., $\ln \left[N_{t}\right]-\ln$ $\left.\left[N_{t-1}\right]\right)(N=$ number of vultures). We asked whether local population growth rate from year to year co-varied across the region, as expected if climate had an overwhelming influence.

Finding considerable evidence for synchronous population dynamics, we next evaluated whether this synchrony might have been driven by two La Niña events, one ending in 1997 and another spanning 1999 (Figure 2). We reasoned that these events might have triggered downturns in local populations throughout the region and so might have had a major synchronising influence. To evaluate this possibility, we repeated the cross-correlation analysis described above while leaving out (without replacement) the interannual growth for each year. We reasoned that leaving out growth rate estimates for years coinciding with drought would yield a suppressed mean correlation coefficient. Any such cases would indicate that drought contributed to the overall synchrony in population dynamics across the region.

\section{Time series analysis of ENSO impact}

We used Auto Regressive Integrated Moving Average (ARIMA) models (Carroll and Pearson 1999, Becerra-Muñoz et al. 2003) to evaluate more directly whether ENSO influenced Indian Vulture population dynamics. Specifically, we asked whether annual population growth rate could be adequately explained by MEI during year $t$ alone or together with MEI during year $t-1$. 


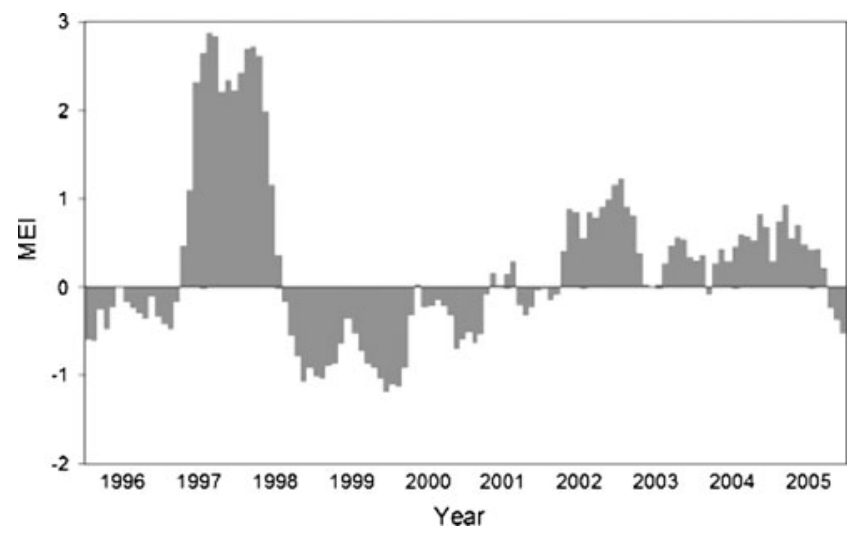

Figure 2. Time series of Multivariate ENSO Index (MEI). Positive MEI values indicate El Niño events and negative values indicate La Niña events.

We used first-order models (i.e. with autoregressive lag term for I year [ARI]). Parameters were set as follows: $P=1$ (lag of 1 year), $d=1$ (time series differenced once to make it stationary, following natural logarithm transformation), and $q=\mathrm{o}$ (order of moving average set to zero).

We used the Akaike Information Criterion (AIC) (Bozdogan 1987) for model selection to evaluate whether the dynamics of each local population were best described by ARI alone, by ARI and $\mathrm{MEI}_{t}$, or by ARI, MEI $I_{t}$ and $\mathrm{MEI}_{t-1}$. Best models were identified as those with minimal AIC values. We used stationary $r^{2}$ as the goodness-of-fit measure.

\section{Time series analysis for individual villages}

We first determined whether the best AIC-based ARIMA model for each village's local population included $\mathrm{MEI}_{t}$ or $\mathrm{MEI}_{t-1}$. If the best model did not include either metric for ENSO then we assumed the local population was somewhat buffered by the negative effects of drought. We next evaluated whether each model including one or both of these MEI predictors had especially poor fit for this local population. Finally, we asked whether each local population's time series showed low autocorrelation (transformation: natural logarithm; differencing: I year), particularly when MEI predictors were included. We thus reasoned that Indian Vulture population dynamics in any village might have been largely independent of MEI and representative of an underlying white noise process.

\section{Results}

\section{ENSO and synchronous population dynamics throughout the region}

The MEI time series (Figure 2) includes two La Niña events, as shown by the prolonged series of negative MEI values extending into 1997 and the subsequent series spanning 1999. Such events can lead to monsoon failure. The major event spanning 1999 caused consecutive monsoon failures leading to a severe vegetative drought throughout Rajasthan in 2000. Our time series of Indian Vulture population growth rates suggests that both of these La Niña events had a latent impact. Table 2 reveals that all 11 local populations shrank from 1997 to 1998 and again from 1999 to 2000. These universal downturns suggest that ENSO-induced drought might have synchronised population dynamics across the region.

Table 3 confirms a high degree of region-wide synchrony. The time series of population growth rates were universally positively correlated across the 55 pairwise combinations of local 
Table 1. Vulture counts from each of the 11 villages, 1996-2005.

Khajarli Sardar Chotila Dugar Nakora Dawra Bijapur Jhala Parshuramji Sumer Dantiwara Samand Chhatri

\begin{tabular}{|c|c|c|c|c|c|c|c|c|c|c|c|}
\hline 1996 & 22 & 30 & 18 & 16 & 21 & 17 & 38 & 16 & 24 & 42 & 39 \\
\hline 1997 & 25 & 39 & 21 & 19 & 25 & 21 & 45 & 19 & 31 & 51 & 48 \\
\hline 1998 & 20 & 29 & 12 & 12 & 12 & 13 & 23 & 11 & 16 & 27 & 21 \\
\hline 1999 & 15 & 22 & 10 & 15 & 14 & 10 & 20 & 12 & 19 & 20 & 20 \\
\hline 2000 & 10 & 15 & 8 & 11 & 12 & 6 & 14 & 10 & 15 & 15 & 15 \\
\hline 2001 & 12 & 18 & 10 & 13 & 10 & 8 & 16 & 7 & 12 & 17 & 10 \\
\hline 2002 & 14 & 16 & 9 & 11 & 14 & 13 & 23 & 8 & 10 & 16 & 12 \\
\hline 2003 & 13 & 17 & 12 & 14 & 12 & 10 & 19 & 5 & 14 & 21 & 16 \\
\hline 2004 & 12 & 15 & 10 & 15 & 14 & 9 & 25 & 6 & 11 & 20 & 14 \\
\hline 2005 & 16 & 17 & 13 & 16 & 13 & 12 & 22 & 6 & 12 & 26 & 14 \\
\hline
\end{tabular}

populations, with 18 of these correlations reaching nominal significance (i.e. $P<0.05$, unadjusted for multiplicity). Our leave-one-out analysis revealed three inter-annual growth rates that most strongly influenced this synchrony. Specifically, leaving out the growth rates for these interannual intervals (1997-1998, 1999-2000 and 1996-1997) suppressed the mean correlation coefficient (0.309, 0.534, and 0.519, respectively) below the original value of 0.564 (i.e. the mean of values in Table 2). The strong region-wide synchrony was driven by the universal downturns in 1998 and 2000, following the two La Niña events (and by the universal upturn from 1996 to 1997) (Table 2).

Time series analysis using ARIMA models further suggests that ENSO influenced population dynamics. Table 4 shows the best AIC-based model included at least one MEI predictor for all eleven villages in the study. Table 5 shows relatively good fit for models including one or both MEI predictors.

\section{Individual village variation in vulture populations under drought conditions}

We report several lines of preliminary evidence that Indian Vultures in several villages were buffered against ENSO impacts. Dugar, Khejarli, and Chotila's respective local populations had the most favourable population growth rates, with Dugar having a net population change of zero (Table 4). Second, for all three of these villages' local populations, the fit of the ARIMA model was the poorest of all when one or both of the MEI predictors were included (Table 5). Lastly,

Table 2. Annual population growth rates of Indian Vultures in each surveyed village, 1996-2005.

\begin{tabular}{|c|c|c|c|c|c|c|c|c|c|c|c|}
\hline Year & Khejarli & $\begin{array}{l}\text { Sardar } \\
\text { Samand }\end{array}$ & Chotila & Dugar & Nakora & Dawra & Bijapur & $\begin{array}{l}\text { Jhala } \\
\text { Chhatri }\end{array}$ & Parshuramji & Sumer & Dantiwara \\
\hline 1996-97 & 0.128 & 0.262 & 0.154 & 0.172 & 0.174 & 0.211 & 0.169 & 0.172 & 0.256 & 0.194 & 0.208 \\
\hline $1997-98$ & -0.223 & -0.296 & -0.560 & -0.460 & -0.734 & -0.480 & -0.671 & -0.547 & -0.661 & -0.636 & -0.827 \\
\hline $1998-99$ & -0.288 & -0.276 & -0.182 & 0.223 & 0.154 & -0.262 & -0.140 & 0.087 & 0.172 & -0.300 & -0.049 \\
\hline 1999-00 & -0.405 & -0.383 & -0.223 & -0.310 & -0.154 & -0.511 & -0.357 & -0.182 & -0.236 & -0.288 & -0.288 \\
\hline 2000-01 & 0.182 & 0.182 & 0.223 & 0.167 & -0.182 & 0.288 & 0.134 & -0.357 & -0.223 & 0.125 & -0.405 \\
\hline 2001-02 & 0.154 & -0.118 & -0.105 & -0.167 & 0.336 & 0.486 & 0.363 & 0.134 & -0.182 & -0.061 & 0.182 \\
\hline $2002-03$ & -0.074 & 0.061 & 0.288 & 0.241 & -0.154 & -0.262 & -0.191 & -0.470 & 0.336 & 0.272 & 0.288 \\
\hline $2003-04$ & -0.080 & -0.125 & -0.182 & 0.069 & 0.154 & -0.105 & 0.274 & 0.182 & -0.241 & -0.049 & -0.134 \\
\hline 2004-05 & 0.288 & 0.125 & 0.262 & 0.065 & -0.074 & 0.288 & -0.128 & 0.000 & 0.087 & 0.262 & 0.000 \\
\hline Mean & -0.035 & -0.063 & -0.036 & 0.000 & -0.053 & -0.039 & -0.061 & -0.109 & -0.077 & -0.053 & -0.114 \\
\hline Variance & 0.057 & 0.053 & 0.082 & 0.064 & 0.099 & 0.134 & 0.109 & 0.083 & 0.100 & 0.094 & 0.124 \\
\hline
\end{tabular}


Table 3. Cross-correlation matrix for time series of annual population growth rate for 11 local populations (named after villages) of the Indian Vulture. All 55 pairwise combinations of time series were positively correlated, indicating region-wide synchrony. Bold face indicates nominal significance $(P<0.05$, unadjusted for multiplicity).

\begin{tabular}{|c|c|c|c|c|c|c|c|c|c|}
\hline & Khejarli & $\begin{array}{l}\text { Sardar } \\
\text { Samand }\end{array}$ & Chotila & Dugar & Nakor & Dawra & Bijapur & $\begin{array}{l}\text { Jhala } \\
\text { Chhatri }\end{array}$ & Parshuramji Sumer Dantiwara \\
\hline \multicolumn{10}{|l|}{ Khejarli } \\
\hline $\begin{array}{l}\text { Sardar } \\
\quad \text { Samand }\end{array}$ & 0.844 & & & & & & & & \\
\hline Chotila & 0.678 & 0.848 & & & & & & & \\
\hline Dugar & 0.387 & 0.649 & 0.764 & & & & & & \\
\hline Nakora & 0.307 & 0.239 & 0.360 & 0.522 & & & & & \\
\hline Dawra & 0.921 & 0.699 & 0.576 & 0.367 & 0.567 & & & & \\
\hline Bijapur & 0.593 & 0.499 & 0.451 & 0.515 & 0.850 & 0.781 & & & \\
\hline $\begin{array}{l}\text { Jhala } \\
\text { Chhatri }\end{array}$ & 0.244 & 0.111 & 0.091 & 0.300 & 0.872 & 0.472 & 0.698 & & \\
\hline Parshuramji & 0.254 & 0.523 & 0.747 & 0.820 & 0.554 & 0.248 & 0.322 & 0.332 & \\
\hline Sumer & 0.727 & 0.860 & 0.965 & 0.739 & 0.468 & 0.633 & 0.581 & 0.235 & 0.721 \\
\hline Dantiwara & 0.371 & 0.457 & 0.655 & 0.641 & 0.785 & 0.456 & 0.600 & 0.535 & 0.862 \\
\hline
\end{tabular}

autocorrelation analysis revealed that annual population growth rates for each of the three villages' respective populations were serially independent (Table 6), as expected for an underlying white noise process. Overall, the Indian Vulture populations in Khejarli, Dawra, and Sumer appeared to be less influenced by the vagaries of ENSO.

\section{Discussion}

We offer several insights regarding population dynamics of the Indian Vulture, a Critically Endangered species of the Indian subcontinent. Population dynamics were synchronous across western Rajasthan, as if a large-scale abiotic driver overwhelmed intrinsic regulatory factors. Our analysis suggests ENSO was the major synchronising factor. In part, a major La Niña-induced drought in 2000 apparently triggered a universal downturn in local populations throughout the region. Despite this widespread synchrony, several local populations appeared to be less

Table 4. Local populations of Indian Vulture ordered from highest to lowest mean population growth rate across the time series, 1996-2005. Also shown are predictor variables included in the best AIC-based ARIMA models.

\begin{tabular}{|c|c|c|}
\hline Village & Pop. Growth Rate (R) & Best \\
\hline Dugar & o & $\mathrm{AR}_{1} ; \mathrm{AR}_{1}+\mathrm{MEI}_{\mathrm{t}}$ \\
\hline Khajarli & -0.035 & $\mathrm{AR}_{1} ; \mathrm{AR}_{1}+\mathrm{MEI}_{\mathrm{t}}$ \\
\hline Chotila & -0.036 & $\mathrm{AR}_{1} ; \mathrm{AR}_{1}+\mathrm{MEI}_{\mathrm{t}}$ \\
\hline Dawra & -0.039 & $\mathrm{AR}_{1} ; \mathrm{AR}_{1}+\mathrm{MEI}_{\mathrm{t}}$ \\
\hline Nakora & -0.053 & $\mathrm{AR}_{1}+\mathrm{MEI}_{\mathrm{t}} ; \mathrm{AR}_{\mathrm{I}}+\mathrm{MEI}_{\mathrm{t}}+\mathrm{MEI}_{\mathrm{t}-1}$ \\
\hline Sumer & -0.053 & $\mathrm{AR}_{1} ; \mathrm{AR}_{1}+\mathrm{MEI}_{\mathrm{t}}$ \\
\hline Bijapur & -0.061 & $\mathrm{AR}_{1}+\mathrm{MEI}_{\mathrm{t}}$ \\
\hline Sardar Samand & -0.063 & $\mathrm{AR}_{1} ; \mathrm{AR}_{1}+\mathrm{MEI}_{\mathrm{t}}+\mathrm{MEI}_{\mathrm{t}-1}$ \\
\hline Parshuramji & -0.077 & $\mathrm{AR}_{1} ; \mathrm{AR}_{1}+\mathrm{MEI}_{\mathrm{t}}+\mathrm{MEI}_{\mathrm{t}-1}$ \\
\hline Jhala Chhatri & -0.109 & $\mathrm{AR}_{1}+\mathrm{MEI}_{\mathrm{t}} ; \mathrm{AR}_{1}+\mathrm{MEI}_{\mathrm{t}}+\mathrm{MEI}_{\mathrm{t}-1}$ \\
\hline Dantiwara & -0.114 & $\mathrm{AR}_{1} ; \mathrm{AR}_{1}+\mathrm{MEI}_{\mathrm{t}}$ \\
\hline
\end{tabular}


Table 5. Goodness-of-fit as measured by stationary $r^{2}$ for first-order ARIMA models. Villages (local breeding populations of Indian Vultures) ordered from best to worst for the model with predictors ARI+MEI .

\begin{tabular}{llll}
\hline & \multicolumn{2}{l}{ Model parameters } & \\
\cline { 2 - 4 } Local population & $\mathrm{AR} \mathbf{1}$ & $\mathrm{AR} \mathbf{1}+\mathrm{MEI}_{t}$ & $\mathrm{AR}_{\mathbf{1}}+\mathrm{MEI}_{t}+\mathrm{MEI}_{t-\mathbf{1}}$ \\
\hline Sardar Samand & 0.035 & 0.729 & 0.730 \\
Dugar & 0.477 & 0.574 & 0.591 \\
Parshuramji & 0.380 & 0.515 & 0.540 \\
Jhala Chhatri & 0.427 & 0.486 & 0.528 \\
Bijapur & 0.036 & 0.407 & 0.567 \\
Nakora & 0.281 & 0.405 & 0.651 \\
Dantiwara & 0.048 & 0.389 & 0.467 \\
Chotila & 0.087 & 0.338 & 0.447 \\
Sumer & $4.7 \times 10-4$ & 0.329 & 0.363 \\
Dawra & $\mathbf{1 . 7} \times \mathbf{1 0}-4$ & 0.287 & 0.318 \\
Khejarli & 0.018 & $\mathbf{0 . 2 7 2}$ & $\mathbf{0 . 2 8 0}$ \\
\hline
\end{tabular}

influenced by ENSO, providing the impetus to further investigate other possible influences on Indian vultures nesting in these villages.

\section{ENSO and Indian Vulture population dynamics}

Our results indicate that ENSO events synchronised Indian Vulture population dynamics throughout western Rajasthan. We suggest that the major La Nina event spanning 1999 might have played a role in triggering the downturn in Indian Vultures throughout western Rajasthan (Chhangani 2005). Until now, diclofenac has been implicated as the major, perhaps only, cause of the widespread decline of this species (Green et al. 2004). Our intent is not to discredit evidence that diclofenac poisoning has played a major causal role or to question IUCN's diclofenac-related rationale for recently listing the Indian, White-backed, and Slender-billed Vulture as 'Critically Endangered'. We simply emphasise that the potentially additive or synergistic role of climate

Table 6. Results of autocorrelation analysis on time series of Indian Vulture count data (transformation: natural logarithm; differencing: 1 year). Smaller Box-Ljung statistic values indicate stronger support for an underlying white noise process. Villages (local breeding populations of Indian Vultures) ordered based on ascending values of this statistic. Local breeding populations of Indian Vulture in villages nearer the bottom of the list were apparently less influenced by ENSO.

\begin{tabular}{llll}
\hline & & \multicolumn{2}{l}{ Box-Ljung statistic } \\
\cline { 3 - 4 } Village & Autocorrelation & Value & $P^{\mathrm{a}}$ \\
\hline Dugar & -0.686 & 5.826 & 0.016 \\
Jhala Chhatri & -0.644 & 5.132 & 0.023 \\
Parshuramji & -0.601 & 4.477 & 0.034 \\
Nakora & -0.53 & 3.475 & 0.062 \\
Chotila & -0.269 & 0.892 & 0.345 \\
Dantiwara & -0.215 & 0.573 & 0.449 \\
Bijapur & -0.19 & 0.446 & 0.504 \\
Sardar Samand & -0.179 & 0.395 & 0.530 \\
Khejarli & 0.112 & 0.155 & 0.694 \\
Sumer & 0.02 & 0.005 & 0.945 \\
Dawra & -0.012 & 0.002 & 0.966 \\
\hline
\end{tabular}

${ }^{\mathrm{a}}$ Two-tailed, based on chi-square distribution $(\mathrm{df}=\mathrm{I})$. 
should not be ignored, especially in an arid region where ENSO-induced drought is now known to cause catastrophic die-offs of vertebrates, even in a protected area and presumably in the absence of diclofenac poisoning (Waite et al. 2007a). Future attempts to model causes of widespread population declines should begin by incorporating the climate cycle as the primary abiotic driver.

\section{Buffering from drought in villages}

While any attempt to understand population dynamics should consider the role of climate, there are several contributing factors, including human activity, that can potentially buffer vertebrate populations against climatic vagaries, even protecting them against catastrophic die-off during drought (Waite et al. 2007b). In keeping with the growing emphasis on community-based conservation in developing countries (Agrawal and Gibson 1999, Lepp and Holland 2006, van Eeden et al. 2006, Sommerville et al. 2010, Waylen et al. 2010, López-Arévalo et al. 2011) we would like to specifically explore the potential impact that humans living in the region may have on Indian Vulture populations. Permanent food and water supply and nesting habitat are factors that are positively associated with sustained vulture populations (Chhangani 2005, Monadjem and Garcelon 2008, Mateo-Tomás and Olea 2010). Future research will further investigate village-specific characteristics such as small cliff formations (Dawra village), large temples (Dugar village), and permanent water bodies (Khejarli and Chotila village) and the potential effects on Gyps vulture populations.

Khejarli village is of particular interest however, because of the presence of a unique caste of local people that may have a positive influence on vulture nesting habitat. The Bishnoi people of western Rajasthan could be an exemplar of built-in community-based conservation of vultures and other species of conservation concern. The Bishnoi faith, founded in 1485 by Jambeshwar, is based on twenty-nine principles ("Bish-noi" translates to "twenty-nine"), one of which specifies doing no harm to any living creature (Fisher 1997, Brockmann and Pichler 2004). In particular, they hold sacred a key tree species, Prosopis cineraria (locally known as the khejeri tree) (Brockmann and Pichler 2004). Bishnoi do not cut off branches of khejeri to feed livestock, thereby presumably providing more favourable nesting habitat for vultures (Brockmann and Pichler 2004). Vulture populations in areas with proper nesting habitat may better maintain village-specific birth rates during drought years where adults may emigrate to other areas or experience greater juvenile mortality. Presumably, vultures would avoid areas where khejeri trees are heavily cut and choose to nest in areas where trees are uncut, specifically areas with relatively high Bishnoi populations.

Though more research is on the subject of a "Bishnoi effect" is necessary, we speculate that a portion of the buffering that occurred in Khejarli village is attributable to the protection practices of the Bishnoi people. The Bishnoi have a long history of protecting this tree. In the year 1730, 363 Bishnoi men, women and children sacrificed their lives in protest at Maharaja Abhay Singh felling khereji trees in Khejarli village for renovation of his palace (Brockmann and Pichler 2004). The Bishnoi, who make up $41 \%$ of the $\sim 1,200$ residents of Khejarli, still actively protect this tree (pers. obs.) and may provide an oasis of suitable, undisturbed nesting habitat for vultures.

Any strong inferences about whether and how Bishnoi activities benefit species of conservation concern cannot, however, be based solely on one species in one village. Future work will expand the geographic scope of this preliminary study and attempt to uncover the underlying basis for how Bishnoi provide a safe haven for endangered wildlife species.

\section{Implications for conservation breeding strategies}

In response to the vulture crisis, a captive breeding programme was initiated eight years ago for Indian, White-backed, and Slender-billed Vultures in Pinjore, India (Vulture Rescue 2008). 
This programme aims to protect remaining populations while giving the country's ban on diclofenac time to take effect, and then to release captive-reared vultures into the wild. Our results prompt two suggestions for those devising strategies for reintroduction. First, given our evidence for region-wide universal downturns of Indian Vulture populations following La Niña events, we suggest that releases should not be scheduled to coincide with ongoing or imminent La Niña events. Straightforward monitoring of MEI data could help to optimise the timing of release.

Second, while releasing captive-reared vultures in protected areas (national parks or wildlife sanctuaries) seems the obvious preferred approach, it is important that the potentially positive effects of human activity on wildlife are also considered. The miraculous recent recovery of Spot-billed Pelicans Pelecanus philippensis in Cambodia (400\% increase in population size in seven years) provides a striking example of successful local community involvement with wildlife conservation (Wildlife Conservation Society 2008). Beyond the speculative benefits provided by their lifestyle, the Bishnoi also opportunistically perform wildlife rescue and rehabilitation, e.g. of injured blackbuck Antilope cervicapra (pers. obs.). Success of recovery efforts succeed depends on the fate of wild populations after reintroduction. Ideally, the ongoing captive breeding efforts will not be squandered by the failure of wild populations in the future. Well-timed release of captiveraised vultures into the wild, combined with local community participation, could improve the prospects for successful recovery of vulture populations.

\section{Conclusions}

We found that Indian Vulture population dynamics were synchronised across a broad region of western Rajasthan, apparently by ENSO events. Although ENSO apparently impacted local populations in a parallel way across this region, some local populations were partially buffered from the effects of drought. Factors contributing to drought buffering, including human activity, are currently being investigated. Future attempts to model the effects of putative causes of widespread vulture declines (e.g. by diclofenac poisoning) should incorporate the potentially significant impact of climate. Ongoing research aims to explore whether and how human activity may directly impact the conservation status of the Indian Vulture and other endangered wildlife species, within officially unprotected areas.

\section{Acknowledgements}

We thank CSIR, New Delhi for S.R.A. ship; Professor D. Mohna, Head of the Department of Zoology, J.N.V. University, U.S. Fish and Wildlife Service, and The School for Desert Sciences for supporting vulture fieldwork; S. M. Mohnot and L. S. Rajpurohit for valuable guidance; P. Robbins for related collaboration; many support personnel; I. Hamilton, E. Marschall, K. McSweeney, and the Waite Lab Group for helpful feedback; Stauf's, Soul Sistas, and Seven Main for providing a pleasant workspace; and NSF grant 0351037.

\section{References}

Agrawal, A. and Gibson, C. (1999) Enchantment and disenchantment: The role of community in natural resource conservation. World Devel. 27: 629-649.

Becerra-Muñoz, S., Buelna-Osben, H. R. and Catalán-Romero, J. M. (2003) Spatial patterns of ARIMA modeled rates of change of atherinids (Chirostoma spp.) and goodeid
Chapalichthys encaustus from Lake Chapala, México. Ecol. Model. 165: 237-250.

BirdLife International (2009) Gyps bengalensis. In: IUCN 2010. IUCN Red List of threatened species. Version 2010.2. <www.iucnredlist. org >. Downloaded on 25 July 2010.

Bozdogan, H. (1987) Model selection and Akaike's information criterion (AIC): the 
general theory and its analytical extensions. Psychometrika 52: 345-370.

Brockmann, H. and Pichler, R. (2004) Paving the way for peace: The living philosophies of Bishnois and Jains. Delhi, India: D.K. Fine Art Press.

Carroll, S. S., and Pearson, D. L. (1999) Detecting and modeling spatial and temporal variance in conservation biology. Conserv. Biol. 14: 1893-1897.

Chaudhary, A., Subedi, T. R., Giri, J. B., Baral, H. S., Bidari, B., Subedi, H., Chaudhary, B., Chaudhary, I., Paudel, K. and Cuthbert, R. J. (in press) Population trends of Critically Endangered Gyps vultures in the lowlands of Nepal. Bird Conserv. Internat. doi:10.1017/So95927091100042

Chhangani, A. K. (2004) Status of a breeding population of long-billed vulture (Gyps indicus) in and around Jodhpur (Rajasthan), India. Vulture News 50: 15-22.

Chhangani, A. K. (2005) Population ecology of vultures in western Rajasthan. Indian Forester 131: 1373-1383.

Chhangani, A. K. and Mohnot, S. M. (2004) Is diclofenac the only cause of vulture decline. Current Sci. 87: 1496-1497.

Chhangani, A. K. and Sivaperuman, C. (2009) Present Status of vultures in the Great Indian Thar Desert. Pp. 65-82 in C. Sivaperuman, Q. H. Baqri, G. Ramaswamy and M. Naseema, eds. Faunal ecology and conservation of the Great Indian Desert. Berlin-Heidelberg, Germany: SpringerVerlag.

Cleary, D. F. R., Fauvelot, C., Genner, M. J., Menken, S. B. J. and Mooers, A. O. (2006) Parallel responses of species and genetic diversity to El Niño Southern Oscillationinduced environmental destruction. Ecol. Lett. 9: 301-307.

Das, D., Cuthbert, R. J., Jakati, R. D. and Prakash, V. (2011) Diclofenac is toxic to the Himalayan Vulture Gyps himalayensis. Bird Conserv. Internat. 21: 72-75.

Ferguson-Lees, J., Christie, D. A., Franklin, K., Philip, B. and Mead, D. (2001) Raptors of the world. London: Houghton Mifflin.

Fisher, R. J. (1997) If the rain doesn't come: An anthropological study of drought and human ecology in western Rajasthan. New Delhi, India: Monohar.
Gilbert, M., Virani, M. Z., Watson, R. T., Oaks, J. L., Benson, P. C., Khan, A. A., Ahmed, S., Chaudhry, J., Arshad, M., Mahmood, S. and Shah, Q. A. (2002) Breeding and mortality of oriental white-backed vulture Gyps bengalensis in Punjab Province, Pakistan. Bird Conserv. Int. 12: 311-326.

Green, R. E., Newton, I., Shultz, S., Cunningham, A. A., Gilbert, M., Pain, D. J. and Prakash, V. (2004) Diclofenac poisoning as a cause of vulture population declines across the Indian subcontinent. J. Appl. Ecol. 41: 793-800.

Green, R. E., Taggart, M. A., Das, D., Pain, D. J., Kumar, C. S., Cunningham, A. A. and Cuthbert, R. A. (2006) Collapse of Asian vulture populations: risk of mortality from residues of the veterinary drug diclofenac in carcasses of treated cattle. J. Appl. Ecol. 43: 949-956.

Harrison, R. D. (2000) Repercussions of El Niño: drought causes extinction and the breakdown of mutualism in Borneo. Proc. R. Soc. B 267: 911-915.

Hernández, M. and Margalida, A. (2008). Pesticide abuse in Europe: effects on the Cinereous Vulture (Aegypius monachus) population in Spain. Ecotoxicology 17: 264-272.

Hernández, M. and Margalida, A. (2009). Poison-related mortality effects in the endangered Egyptian vulture (Neophron percnopterus) population in Spain. Eur. J. Wildl. Res. 55: 415-423.

Hla, H., Shwe, N. M., Htun, T. W., Zaw, S. M., Mahood, S., Eames, J. C. and Pilgrim, J. D. (in press) Historical and current status of vultures in Myanmar. Bird Conserv. Internat. doi:10.1017/S095927091000056o

Holmgren, M. and Scheffer, M. (2001) El Nino as a window of opportunity for the restoration of degraded arid ecosystems. Ecosystems 4: 151-159.

IUCN (2007) IUCN Red list of Threatened Species. http://www.iucnredlist.org, accessed March 29, 2008. IUCN, Gland Switzerland.

Jackson, R. and Wangchuk, R. (2004) A community-based approach to mitigating livestock depredation by snow leopards. Hum. Dimensions Wildl. 9: 307-315.

Lepp, A. and Holland, S. (2006) A comparison of attitudes toward state-led conservation and community-based conservation in the 
village of Bigodi, Uganda. Soc. Nat. Resour. 19: 609-623.

López-Arévalo, H. F., Gallina, S., Landgrave, R., Martinez-Meyer, E. and Muñoz-Villers, L. E. (2011) Local knowledge and species distribution models contribution towards mammalian conservation. Biol. Conserv. 144: 1451-1463.

Margalida, A., Heredia, R., Razin, M. and Hernandez, M. (2008) Sources of variation in mortality of the Bearded Vulture Gypaetus barbatus in Europe. Bird Conserv. Int. 18: 1-10.

Mateo-Tomás, P. and Olea, P. P. (2010) When hunting benefits raptors: a case study of game species and vultures. Eur. J. Wildl. Res. 56: 519-528.

Monadjem, A. and Garcelon, D. K. (2008) Nesting distribution of vultures in relation to land use in Swaziland. Biodiv. Conserv. 14: 2079-2093.

Oaks, J. L., Gilbert, M., Virani, M. Z., Watson, R. T., Meteyer, C. U., Rideout, B. A., Shivaprasad, H. L., Ahmed, S., Chaudhry, M. J. I., Arshad, M., Mahmood, S., Ali, A. and Khan, A. A. (2004) Diclofenac residues as the cause of vulture population decline in Pakistan. Nature 427: 630-633.

Prakash, V. (1999) Status of vultures in Keoladeo National Park, Bharatpur, Rajasthan, with special reference to population crash in Gyps species. J. Bombay Nat. Hist. Soc. 96: 365-378.

Prakash, V., Pain, D. J., Cunningham, A. A., Donald, P. F., Prakash, N., Verma, A., Gargi, R., Sivakumar, S. and Rahmani, A. R. (2003) Catastrophic collapse of white-backed Gyps bengalensis and long-billed Gyps indicus vulture populations. Biol. Conserv. 109: 381-390.

Rasmussen, P. C. and Parry, S. J. (2001) The taxonomic status of the "longbilled" vulture Gyps indicus. Vulture News 44: 18-21.

Roach, C. M., Hollis, T. I., McLaren, B. E. and Bavington, D. (2006) Ducks, bogs, and guns. Ethics and the Environment 11: 43-70.

Shultz, S., Baral, H. S., Charman, S., Cunningham, A. A., Das, D., Ghalsasi, G. R., Goudar, M. S., Green, R. E., Jones, A., Nighot, P., Pain, D. J. and Prakash, V. (2004) Diclofenac poisoning is widespread in declining vulture populations across the Indian subcontinent. Proc. Roy.Soc. London, B (Supplement) 271: $\mathrm{S}_{458-S_{4} 60 .}$

Sommerville, M., Milner-Gulland, E. J., Rahajaharison, M. and Jones, J. P. G. (2010) Impact of a community-based payment for environmental services intervention on forest use in Menabe, Madagascar. Conserv. Biol. 24: 1488-1498.

SPSS (2007). SPSS. Version 15.0. Chicago, USA: SPSS Inc.

Swan, G. E., Cuthbert, R., Quevedo, M., Green, R. E., Pain, D. J., Bartels, P., Cunningham, A. A., Duncan, N., Meharg, A. A., Oaks, J. L., Parry-Jones, J., Shultz, S., Taggart, M. A., Verdoorn, G. and Wolter, K. (2006) Toxicity of diclofenac to Gyps vultures. Biol. Lett. 2: 279-282.

Taggart, M. A., Cuthbert, R., Das, D., Sashikumar, C., Pain, D. and Green, R. (2006) Disposition of diclofenac in Indian cow and goat with reference to Gyps vulture population declines. Environ. Pollution doi:10.1016/ j.envpol.2006.08.017.

Taggart, M. A., Senacha, K. R., Green, R. S., Jhala, Y. V., Raghavan, B., Rahmani, A. R., Cuthbert, R., Pain, D. J. and Meharg, A. A. (2007) Diclofenac residues in domestic ungulates available to vultures in India. Environ. Int. 33: 759-765.

van Eeden, D. G., van Rensburg, B. J., De Wijn, M. and Bothma, J. (2006) The value of community-based conservation in a heterogeneous landscape: an avian case study from sand forest in Maputaland, South Africa. South Afr. J. Wildl. Res. 36: 153-157.

Vulture Rescue (2008) Vulture conservation breeding centres. Pinjore, India: Vulture Rescue. Available online at: http://www. vulturerescue.org/page8.html. Accessed 12 April 2008.

Waite, T. A., Campbell, L. G., Robbins, P. and Chhangani, A. K. (2007a) La Niña's signature: synchronous decline of the mammal community in a 'protected' area in India. Divers. Distrib. 13: 752-760.

Waite, T. A., Chhangani, A. K., Campbell, L. G., Rajpurohit, L. S. and Monot, S. M. (2007b) Sanctuary in the city: urban monkeys buffered against catastrophic die-off from ENSO induced drought. EcoHealth 4: 278-286. 
Waylen, K. A., Fischer, A., McGowan, P. J.K., Thirgood, S. J. and Milner-Gulland, E. J. (2010) Effect of local cultural context on the success of community-based conservation interventions. Conserv. Biol. 24: 11191129 .
Wildlife Conservation Society (2008) Asian water birds stage remarkable comeback. Science Daily. Available online at: http:// www.sciencedaily.com/releases/2008/04/ 080403125426.htm. Accessed 12 April 2008.

\section{JONATHAN C. HALL*, TOM A. WAITE, IAN M. HAMILTON}

Department of Evolution, Ecology, and Organismal Biology, Ohio State University, Columbus, Ohio 43210, USA.

Department of Mathematics, Ohio State University, Columbus, Ohio 43212, USA.

\section{ANIL K. CHHANGANI}

Department of Zoology, JNV University, Jodhpur 342001, India.

*Author for correspondence; e-mail: hall.1073@osu.edu

Received 19 October 2010; revision accepted 29 April 2011;

Published online 5 December 2011 